\title{
REFLEXÕES SOBRE A CONFLITIVA COM A LEI NA ADOLESCÊNCIA: CONTEXTOS EXCLUDENTES, FAMÍLIAS "INVISÍVEIS"
}

\author{
REFLECTIONS UPON THE CONFLICT WITH THE LAW IN ADOLESCENCE: EXCLUDING \\ CONTEXTS, "INVISIBLE" FAMILIES \\ REFLEXIONES SOBRE EL CONFLICTO CON LA LEY EN LA ADOLESCENCIA: CONTEXTOS DE \\ EXCLUSIÓN, FAMILIAS "INVISIBLES"
}

\author{
Renata Petry Brondani* \\ Dorian Mônica Arpini*
}

\begin{abstract}
RESUMO
Considerando os contextos de invisibilidade a que muitas famílias estão expostas, este estudo procurou problematizar algumas especificidades do público atendido por uma instituição de cumprimento da medida socioeducativa de internação no Estado do Rio Grande do Sul. Para atingir o objetivo de uma pesquisa qualitativa, foram realizadas dez entrevistas semiestruturadas, sendo estas com cinco adolescentes e cinco respectivos familiares. Também foram acessados os prontuários dos adolescentes na instituição, complementando os dados por meio de uma fonte documental. A análise dos resultados obtidos enuncia semelhanças nas experiências das famílias como: residência na periferia; profissóes que colocam em uma posição de baixa renda; famílias com número de filhos superior ao da taxa de fecundidade; baixa escolaridade; e maternidade na adolescência. Diante disso, compreende-se que tais famílias convivem com sofrimentos e vulnerabilidades, mas que, sobretudo, deve-se buscar superar os obstáculos mediante o fortalecimento dos laços que os unem.
\end{abstract}

Palavras-chave: Famílias. Invisibilidade social. Exclusão social. Ato infracional. Medida socioeducativa.

\begin{abstract}
Bearing in mind the context of invisibility to which many families are exposed, this study aimed to approach some characteristics of the public assisted by an institution in charge of socio-educational measures of confinement for youngsters in the state of Rio Grande do Sul, Brazil. In
\end{abstract}

\footnotetext{
Mestra e graduada em Psicologia pela Universidade Federal de Santa Maria (UFSM), atualmente atua como Psicóloga em uma instituição de acolhimento de crianças e adolescentes.

"* Doutora em Psicologia Social pela Pontifícia Universidade Católica de São Paulo (2001) e pós-doutorado em Psicologia pela Universidade de Lisboa (2014). Atualmente é professora titular da UFSM, membro do GT da ANPEPP: A Psicologia sóciohistórica e o contexto brasileiro de desigualdade social. Integra o grupo de Pesquisa Núcleo de Estudos Interdisciplinares em Saúde (Diretório Pesquisa CNPq).
} 
order to achieve the objectives of a qualitative research, ten semi-structured interviews were carried out, five of them with five adolescents and other five focusing the teenagers' family members. The adolescents' institution reports were also investigated and a documental source was used to get to overall data. Data analysis unveils similarities in these family experiences such as: slum residences; low payment jobs; families with number of children superior to fertility rate; poor education level and teenage pregnancy. Having that in mind, it is understood that those families live with sufferings and vulnerabilities, which lead them to overcome obstacles through the strengthening of their bonds.

Keywords: Families. Social invisibility. Social exclusion. Infractional act. Socio-educational measure.

\section{RESUMEN}

Considerando los contextos de invisibilidad a que muchas familias están expuestas, esta investigación buscó problematizar algunas características del público de una institución de cumplimiento de intervención socioeducativa de internamiento en Rio Grande do Sul, Brasil. Para alcanzar el objetivo de esta investigación cualitativa, se hicieron diez entrevistas semiestructuradas - cinco con adolescentes y otras cinco con miembros de sus familias. También se accedieron los registros de la institución acerca de los adolescentes, la fuente documental de los datos. El análisis de los resultados presenta semejanzas en las experiencias de las familias como: residencias periféricas; profesiones de menores ingresos; familias con número de hijos superior a la tasa de fecundidad; bajo nivel de escolaridad; maternidad en la adolescencia. Así, se concibe que esas familias viven con sufrimientos y vulnerabilidades, sin embargo, deben buscar superar las dificultades a través del fortalecimiento de los lazos.

Palabras clave: Familias. Invisibilidad social. Exclusión social. Acción infraccional. Intervención socioeducativa.

\section{INTRODUÇÃO}

família faz parte do universo de experiências que constitui os seres humanos
e abordar esse tema nos aproxima de uma temática repleta de significados
afetivos para cada indivíduo, que, como ser biopsicossocial, está inserido em um ambiente, integrando a cultura e seu grupo social de pertença. Tais aspectos levam à compreensão da família de modo contextualizado, considerando a subjetividade que a permeia e lhe é inerente (Gomes \& Pereira, 2005).

Os diferentes contextos familiares buscam no cotidiano dividir não somente as emoções dos laços familiares, mas também as angústias que lhes apresentam. A 
manifestação cotidiana da desigualdade social existente traz o retrato de famílias que, cada vez mais, são apartadas do acesso ao mínimo de sobrevivência, em contextos de exclusão. A família, na sociedade contemporânea, encontra o desafio de sobreviver e de continuar exercendo seu papel (Moreira, Passos, \& Pereira, 2012; Oliveira, 2009). Nesse sentido, a temática da exclusão social representa uma questão complexa e multifacetada, com dimensões materiais, políticas, relacionais e subjetivas. A exclusão, como um processo sutil e dialético, só existe em relação à inclusão e como parte constitutiva dela. Por ser um processo que envolve o sujeito e as suas relações com os outros, é influenciada por formas diferenciadas de legitimação social e individual (Sawaia, 1999).

Assim, a exclusão social pode se concretizar a partir de diferentes formas. Uma delas e, talvez a mais grave, diz respeito à exclusão econômica, visto que pode gerar outros tipos de exclusão, como a cultural, territorial e étnica. No que concerne à segregação cultural, há uma privação do indivíduo de obtenção da escolaridade, sendo esse um importante instrumento de acesso à informação e exercício da plena cidadania. Já a exclusão territorial afasta o cidadão do convívio com o restante da sociedade, o acesso ao emprego e à escola. Por fim, a exclusão étnica classifica como inferiores e diferentes um determinado grupo. Todas essas formas de exclusão levam os sujeitos a vivenciarem um conjunto de vulnerabilidades que operam como obstáculos difíceis de serem superados na sociedade (Feijó \& Assis, 2004; Rodrigues \& Sousa, 2017).

O termo exclusão social tem, portanto, sentido temporal e espacial, pois um grupo pode ser considerado excluído segundo determinado espaço geográfico ou em relação à estrutura e conjuntura econômica e social. Como reflexo das transformaçôes ocorridas no Brasil, acentuam-se as desigualdades sociais e de renda das famílias, afetando as condições de sobrevivência e minando as expectativas de superação desse estado de pobreza, além de que podem reforçar a submissão aos serviços públicos existentes. As desigualdades de renda impõem sacrifícios e renúncias para todos os membros da família (Gomes \& Pereira, 2005).

Por isso o conceito de exclusão compreende um processo que ocorre efetivamente pelo estado daqueles que se encontram fora dos circuitos vivos das trocas sociais. O excluído pode ser considerado um "desfiliado", cuja trajetória é constituída por uma série de rupturas em relação a estados de equilíbrio anteriores, mais ou menos estáveis ou instáveis (Castel, 1997). Essa condição reverbera na falta de ganhos, alojamento, cuidados, instrução, atenção e na possibilidade de exercício da cidadania, considerando que a falta de acesso às diferentes oportunidades para o indivíduo e para a família pode afetar o sentido de sua existência e as expectativas de futuro (Feijó \& Assis, 2004; Rodrigues 
\& Sousa, 2017). Embora não se constituam como sinônimos de uma mesma situação de ruptura, a pobreza leva a formas de ruptura do vínculo social e representa um acúmulo de precariedades. No Brasil, a pobreza e a exclusão são faces de uma mesma moeda, visto que existem altas taxas de concentração de renda e de desigualdade. Com isso, ressalta-se que a consolidação de um país democrático deverá promover uma desnaturalização de diferenças e práticas discriminatórias que perpetuem processos de exclusão (Wanderley, 1999).

Com base nisso, ressalta-se que a família e a sua capacidade protetiva com relação a seus membros, especialmente crianças e adolescentes, é também influenciada pela manifestação dessas questōes sociais. Os contextos sociais podem exercer grande influência tanto sobre a configuração quanto sobre a própria organização familiar, expressando diversidades em suas relaçôes interiores. As contradições sociais que se fazem presentes na atualidade trazem um cenário no qual as famílias convivem com a violência e as manifestações dela decorrentes. Muitas vezes, os pais não sabem como evitar que seus filhos adentrem nesse mundo e buscam a educação deles de diversificadas maneiras, e nem sempre alcançam resultados que atendem a suas expectativas (Oliveira, 2009; Silvestre, 2013).

O histórico diferenciado de acesso aos recursos, tanto de ordem material como de ordem simbólica, caracteriza o contexto no qual as pessoas se desenvolvem, constroem suas subjetividades e percorrem suas trajetórias de vida (Santos, Mota, \& Silva, 2013). Diante dessa realidade, as políticas sociais têm encontrado dificuldades para reduzir o quadro de pobreza e de exclusão, considerando as expressivas taxas de desigualdade social (Oliveira, 2009). Assim, persiste um grande número de famílias invisíveis aos olhos do Poder Público e destituídas do atendimento a suas necessidades, que deveriam ser essenciais (Moreira et al., 2012).

Esses conceitos, de exclusão e vulnerabilidade, quando transpostos para as trajetórias de vida e realidade das famílias brasileiras, evidenciam situações de fragilidade das quais crianças e adolescentes ainda estão sendo vítimas. Não se tem conseguido romper ciclos excludentes, desumanos e desiguais, visto que os jovens cidadãos se constituem e convivem com esses contextos. Salienta-se que, posteriormente, esses mesmos jovens cumprem esses ciclos, pois, quando adultos, podem permanecer encontrando dificuldades na consolidação de processos mais inclusivos.

Considerando as especificidades sociais, culturais, políticas e econômicas que, hegemonicamente, caracterizam os adolescentes e as famílias atendidas pelo sistema socioeducativo, evidencia-se que esses convivem em contextos permeados por diversas fragilidades e, consequentemente, pela exclusão social. Este, 
portanto, será o tema abordado neste artigo, que apresenta um recorte de uma pesquisa que teve como objetivo compreender as repercussões do cumprimento da medida socioeducativa de internação na percepção de adolescentes e de familiares.

\section{MÉTODO}

Realizou-se uma pesquisa qualitativa, por contemplar adequadamente investigações de grupos e segmentos delimitados, de histórias sociais, sob a ótica dos atores, de relaçóes e para análises de discursos e documentos (Minayo, 2014). O delineamento deste estudo é o estudo de caso, utilizado na modalidade de estudo de casos múltiplos, compreendendo que cada caso em particular consiste em um estudo completo e são as conclusões de cada caso individual que necessitam de replicação por meio de outros casos individuais (Yin, 2005).

Foram utilizadas duas formas de coleta de dados: a pesquisa documental e a realização de entrevistas semiestruturadas. A análise documental foi realizada pelo acesso aos prontuários dos adolescentes na instituição onde a pesquisa foi realizada. Todavia o principal instrumento utilizado para a coleta de dados foi a entrevista semiestruturada.

Integraram esta pesquisa dez participantes, sendo cinco adolescentes que estavam cumprindo a medida socioeducativa de internação e cinco respectivos familiares desses adolescentes. $O$ estudo se efetivou em uma unidade de cumprimento da medida socioeducativa de internação do Estado do Rio Grande do Sul. Faz-se importante salientar que, entre os familiares que aceitaram participar, todas eram mães dos adolescentes. Foram atendidas todas as exigências da ética em pesquisa e as Diretrizes e Normas Regulamentadoras Envolvendo Pesquisas com Seres Humanos. Obteve-se aprovação do Comitê de Ética em Pesquisa da Universidade pela qual o estudo foi realizado, sendo aprovada sob CAAE 84187418.2.0000.5346.

Para a análise dos dados obtidos, utilizou-se uma das cinco técnicas propostas por Yin (2005), a síntese de casos cruzados. Essa técnica se aplica especificamente à análise de estudos de casos múltiplos. Com base nela, pode-se contar com mais de uma fonte de dados, partindo da compreensão dos casos individuais. Portanto os dados obtidos foram analisados em profundidade; primeiramente, de forma individual, e, em um segundo momento, em seu conjunto, pelo cruzamento dos dados individuais. 


\section{RESULTADOS E DISCUSSŌES}

Pensando em problematizar alguns aspectos do público que é majoritariamente atendido pelas instituições de medidas socioeducativas de internação, os resultados e as discussões abordam algumas características e especificidades que puderam ser percebidas a respeito dos contextos sociais nos diferentes núcleos familiares, assim como relacioná-los com outros autores que abordaram e pesquisaram sobre esses aspectos.

Uma primeira questão a ser considerada diz respeito aos bairros de onde advêm as famílias integrantes deste estudo. Em geral, são famílias que residem em bairros periféricos da cidade onde a unidade socioeducativa se situa. Além disso, são locais usualmente lembrados e já reconhecidos pela violência. $\mathrm{Na}$ pesquisa de Souza e Costa (2013), a qual foi realizada no contexto de uma unidade socioeducativa de internação, também se constatou que as famílias residiam em locais de maior vulnerabilidade social, assim como Medeiros e Paiva (2015) observaram que a maior parte das famílias atendidas vivencia condições concretas de acesso precário aos direitos sociais básicos e diversas problemáticas relacionadas e advindas dessa situação. Salienta-se que os territórios das periferias urbanas não se caracterizam apenas como o lugar onde acontecem as rotinas diárias, mas também como um espaço onde se convive e se compartilham os pressupostos da sociabilidade, da confiança, das trocas, dos favores e das redes de interação (Guimarães, 2011).

É por essa compreensão de um território vivo que Broide (2010) aborda que os espaços urbanos da periferia podem ser definidos "enquanto um lugar sem acesso aos bens sociais e aos ganhos da cultura". O autor ainda refere que o afastamento do Estado desses territórios reverbera em ausências de trabalho formal que se associam à penetração do tráfico de drogas e outras atividades ilícitas. Com isso se constitui uma porosidade cada vez maior entre o mundo formal e o informal, e entre o lícito e o ilícito. Segundo Soares (2004), está em funcionamento no Brasil, nos bairros pobres, nas vilas, favelas e periferias, uma organização do tráfico e do crime. Nesses territórios, duas possibilidades cotidianamente se apresentam para a população: ou se adere a esse contexto ou se convive, porta a porta, com essa situação, gerando tensões em relação aos filhos e às cenas cotidianas de violência (Broide, 2010).

Desse modo, mesmo os jovens que nunca estiveram inscritos no "mundo do crime" não podem se esquivar de estar em contato com ele, pois o modo como as fronteiras "do crime" se aproximam de suas famílias e circuitos sociais é múltiplo e evidente. Para os adolescentes nascidos em famílias de baixa renda, nas periferias das cidades, o "mundo do crime" é algo com que se é preciso lidar, 
visto que coexistem o "mundo legítimo", dos trabalhadores, e o "mundo do crime", ou seja, é algo instituído em suas vidas. Todavia os adolescentes pobres, por si só, já seriam associados à periculosidade por habitarem locais que são percebidos como degradantes. Assim, difunde-se uma percepção que tende a igualar jovens pobres e de periferia como desordeiros perigosos (Feltran, 2008; Salles, Silva, \& Fonseca, 2014).

Oliveira (2001), no entanto, problematiza que os sujeitos que vivem na periferia seriam como uma árvore desprotegida, em que todos que por ela passam retiram-lhe folhas e galhos, isto é, arrancam-lhes algo de valor. Quando esse sujeito resolve buscar o que lhe roubaram, é posto atrás das grades pelo sistema, em um ato de proteger a sociedade desse mesmo jovem, mas também escondendo a beleza da árvore que foi referida. Assim a mesma sociedade que clama pelo aprisionamento, buscando a punição e a repreensão, anteriormente também retirou desses jovens as oportunidades e direitos que deveriam ter sido seus. A exacerbada busca por um lugar deflagrada nesses territórios pela condição de "sem-lugar" que lhes é imposta ocorre porque "o delinquente juvenil é um adolescente desalojado que busca o reconhecimento" (Oliveira, 2001, p. 56).

Com base nessas discussões, outro aspecto importante diz respeito às atividades laborais exercidas pelos familiares (mães, pais e padrastos) dos adolescentes deste estudo, conforme os dados coletados: diaristas, empregadas domésticas, cozinheiro, auxiliar de gesseiro, pizzaiolo, marceneiro, pintor, segurança, ou ainda, desempregados. Cabe destacar que, em alguns casos, os familiares não tinham carteira assinada. De forma semelhante a esses resultados, na pesquisa realizada por Monteiro e Rocha (2013), revelou-se que a maioria dos familiares de adolescentes em conflito com a lei são trabalhadores do mercado informal, sem vínculos empregatícios, mencionando profissões como domésticas, ambulantes, feirantes, vendedores de pequenas mercadorias, pedreiros e desempregados. As condições em que os sujeitos se encontram poderiam ser significadas como produto de relaçôes sociais excludentes e marginalizadoras, afetando tanto homens quanto mulheres. Nessa perspectiva, Medeiros e Paiva (2015) constataram que o público atendido nas unidades de privação de liberdade é advindo de uma classe social bem definida, compreendendo famílias que vivem em situação de pobreza e extrema pobreza.

Em uma sociedade na qual o trabalho define posições com base na segmentação da sociedade, ele costuma adquirir um caráter de centralidade na rotina das famílias (Patto, 2010). Sobre esse aspecto, pode-se pensar que a carência material, a ausência de redes sociais e dos benefícios da cultura trazem graves consequências para aqueles que os vivenciam. Nesses contextos de precariedades, tornam-se necessários grandes investimentos psíquicos defensivos contra a dor da privação. 
Assim, a alternativa que parece ser viável é a do alívio imediato das pressões, as quais frequentemente resultam no uso de drogas e álcool. Esses aspectos vão sendo introjetados através da vida familiar, a qual estaria plenamente permeada pelas relações sociais mais amplas (Broide, 2008).

Todavia as famílias pobres não são constituídas por pais menos amorosos, mas sim por famílias com menos oportunidades de organizar as responsabilidades profissionais de modo a privilegiar a presença em casa, sobretudo com os filhos pequenos. Ademais, também teriam menos chances de contar com apoio nos momentos de crise e disporiam de menos recursos para mobilizar profissionais quando existem dificuldades provocadas ou não por sofrimento psíquico. Assim as famílias de baixa renda estão mais expostas à angústia e insegurança, enfrentando com mais frequência tensões que desestabilizam emoções e corroem a autoestima. Ou seja, ainda que não haja relações causais, diretas e mecânicas, há correlações entre fatores que pertencem a um mesmo campo de fenômenos (Soares, 2004).

$\mathrm{Na}$ perspectiva de Sales (2007), no contexto de adolescentes autores de atos infracionais, estaria configurada uma cidadania denegada, pressupondo uma cisão entre direitos e a questão da violência, isto é, não deveriam ter a oportunidade de acesso aos direitos, justamente pelo envolvimento com a violência. Os adolescentes seriam, assim, duplamente desrespeitados: tanto pela condição de cidadania escassa quanto pela associação indiscriminada entre esse público com o contexto infracional.

Assim o fenômeno do conflito com a lei também pode ser pensado como resultado de conjunturas políticas, culturais, sociais e econômicas. As crianças, adolescentes e suas respectivas famílias, que precisam da atenção do Estado para ter acesso aos direitos básicos, frequentemente esbarram na oferta mínima e inadequada de políticas sociais, encontrando dificuldades para superar as barreiras existentes e, assim, permanecendo à margem da sociedade e invisíveis (Souza $\&$ Costa, 2013). Por isso se defende que a promoção de mudanças concretas nas condições de vida e acesso aos direitos das famílias nesses contextos é urgente, para que se possam vislumbrar formas de inserção e acesso aos bens socialmente valorizados, para além de um envolvimento com atos infracionais (Medeiros $\&$ Paiva, 2015).

Somando-se às profissões que foram mencionadas pelas famílias, constatouse também a questão do número de filhos das mães participantes: três mães mencionaram ter quatro filhos; uma mãe, cinco filhos; e outra, oito filhos. No Brasil, a taxa de fecundidade (que consiste em uma estimativa do número médio de filhos que uma mulher tem ao longo da vida), no ano de 2015, foi de 1,72 
filhos (Instituto Brasileiro de Geografia e Estatística [IBGE], 2015). Diante disso, percebe-se que as mães deste estudo estão acima dessa média nacional e que esse também passa a ser considerado um aspecto que contribui para o incremento das dificuldades e questões financeiras dos contextos familiares desta pesquisa.

Outro aspecto a ser analisado diz respeito ao estado civil das mães participantes. Duas delas permaneciam com os pais dos adolescentes, outras duas estavam em relacionamentos com novos companheiros, e uma não se encontrava em nenhum relacionamento. De acordo com as classificações propostas por Sousa e Peres (2002): duas famílias teriam a configuração nuclear simples (constituída pelo casal, e ambos tiveram apenas uma união e têm ou já tiveram filhos); duas famílias com a configuração nuclear reconstituída (família é formada pelo casal, e um ou ambos os cônjuges já tiveram mais de uma união conjugal, tendo ou não filhos); e uma família monoparental feminina simples (família cuja organização se dá em torno de uma figura feminina - mãe -, com estado civil variado, que não tem companheiro coabitando, com filhos de uma ou mais uniões).

Em contrapartida aos resultados dessa pesquisa, no estudo de Rocha (2010) constatou-se que a configuração priorizada foi a de famílias do tipo monoparental feminino, cuja mãe é a figura central na estruturação financeira e, ou, emocional da família. Já de acordo com Monteiro e Rocha (2013), em uma pesquisa com familiares de adolescentes em cumprimento da medida socioeducativa de internação, constatou-se que a maioria dos pais dos adolescentes eram separados. No entanto a separação em si não se constitui um problema para os filhos, de forma que não se deve estabelecer uma relação direta entre a separação e o fato dos adolescentes envolverem-se com a prática de atos infracionais. Esses aspectos também foram apontados por Feijó e Assis (2004), quando constataram que a maioria dos entrevistados provém de famílias em que os pais se separaram ou que os genitores abandonaram os filhos e suas mães morreram, ou ainda, formaram outras famílias, com novos companheiros.

Também se percebeu que algumas das mães participantes iniciaram suas experiências com a maternidade ainda na adolescência, com 16 e 17 anos, sendo que essas experiências não necessariamente ocorreram com os adolescentes também participantes, mas com outros filhos mais velhos. Outro aspecto a ser considerado é o fato de que um dos adolescentes deste estudo também se tornou pai aos 16 anos. A forma como essas situações de gravidez podem ser vividas irão adquirir um curso individual e único, de acordo com as características contextuais em que ocorreram. Por esse motivo, tornar-se pai e mãe na adolescência, por si só, não pode ser descrito como fator de risco ou de proteção (Cerqueira-Santos, Paludo, Schirò, \& Koller, 2010). Nessa perspectiva, Kehl (2008) destaca que não há nada de errado em si na gravidez na adolescência, pois, biologicamente, 
os adolescentes já entraram na fase reprodutiva. No entanto, frequentemente, quando jovens, a gravidez acaba por ser assumida como uma forma de preencher o vazio de vidas que podem estar sem perspectivas e projetos. Assim, a autora pontua o crescimento de uma geração de filhos da adolescência sem projeto, tal como o fenômeno de "filhos da mãe", com pais ausentes e desconhecidos.

Salientando a complexidade e as possibilidades nas situações de gravidez na adolescência, aponta-se também para o fato de que a gravidez e os filhos têm sido apontados como o principal motivo citado pelas próprias mães para a interrupção dos estudos, ou também pela necessidade de trabalhar que, no entanto, aparecem com maior frequência em casos de pais adolescentes (Almeida, 2008).

Em relação à questão da escolaridade, entre os adolescentes, de forma unânime, constatou-se a defasagem escolar em relação às idades que têm. Essas questões também têm sido foco de estudos que relacionam a temática da escolaridade com o cometimento de atos infracionais por adolescentes. A existência de dificuldades de vinculação com o contexto escolar é recorrente nos discursos desse público, por falta às aulas, evasão escolar, repetência ou dificuldades nas relações entre professor e aluno. Diante disso, conclui-se que a frequência escolar é um importante fator de proteção para as vulnerabilidades existentes (Brondani \& Arpini, 2019; Rolim, 2016; Tejadas, 2007).

Quanto à escolaridade das mães dos adolescentes, duas delas haviam completado o ensino médio (sendo que uma delas o concluiu quando adulta, pela educação de jovens e adultos [EJA]), outra mãe tem o ensino médio incompleto, outra o ensino fundamental completo e, por fim, uma das mães não concluiu o ensino fundamental. Uma das possibilidades para que a escolarização não seja prioridade pode ser em razão do sentimento de que o estudo não contribuirá ou não lhes dará retorno, pois o que se aprende na escola pode não ser utilizado posteriormente (Arpini, 2003).

Pelas considerações sobre as famílias desta pesquisa, percebeu-se a existência de vulnerabilidades e fatores de risco que possivelmente marcaram suas trajetórias. Faz-se significativo observar que os adolescentes de contextos sociais excludentes e vulneráveis são o público majoritário do contexto socioeducativo e também, consequentemente, os demais membros da família. No entanto é importante não realizar análises descontextualizadas sobre essas famílias, criando modelos idealizados que poderiam reforçar sentimentos de culpabilização e responsabilização das famílias pelas vulnerabilidades vivenciadas e, consequentemente, pelas dificuldades para realização da proteção (Silvestre, 2013). 


\section{CONSIDERAÇŌES FINAIS}

Os resultados e as discussões propostos neste artigo revelam a complexidade que representa a temática da família em contextos socioeducativos. As cenas e tramas familiares que compuseram o trabalho evidenciaram famílias com conflitos, sofrimentos, vulnerabilidades e inseguranças, mas, sobretudo, famílias que convivem com situações que as colocam em contextos de exclusão social. Pelo entendimento de que se trata de questôes sociais mais abrangentes e de que essas experiências trazem repercussões psíquicas, compreende-se que tais ressonâncias devem ser consideradas e abordadas nas intervenções proporcionadas pelas instituiçôes socioeducativas, pois podem estar relacionadas ao cometimento de atos infracionais.

Refletir e fomentar questionamentos a respeito das sucessivas falhas anteriores que não puderam suprir e amparar os adolescentes, em conformidade com sistema de garantia de direitos, faz-se fundamental, já que muitas crianças, adolescentes e famílias são invisíveis aos olhos dos dispositivos que deveriam dar conta de apoiá-las e instruí-las. Há de se investir para que, em contextos de internação, as famílias possam ser, finalmente, visíveis ainda que em uma situação extrema e agravada, pois este seria o último recurso disponível para casos de cometimento de atos infracionais. No entanto, mesmo que o panorama seja, em um primeiro momento, considerado desfavorável, já que chegaram até essas instituições, delas poderiam surgir outras possibilidades, mas estas, certamente, demandam investimento.

Reitera-se a importância de que o trabalho com essas famílias não detenha um olhar descontextualizado da realidade social desse público, pois, assim como foi apontado, as famílias dos adolescentes que integram essas instituições provêm, em sua maioria, de bairros periféricos, com profissōes que lhes conferem uma classe social também definida, com um número de filhos acima das médias nacionais e com escolaridade baixa. Diante disso, as intervenções realizadas devem contemplar tais especificidades, por meio de estratégias e encaminhamentos que também busquem atingir tais desafios. Assim, salienta-se que a internação, é uma situação provisória nas trajetórias de vida das famílias, mas que pode adquirir uma potencialidade para gerar um impacto significativo, articulando-se com outros serviços da rede para um trabalho conjunto e complementar. 


\section{REFERÊNCIAS}

Almeida, M. C. C. (2008). Gravidez na adolescência e escolaridade: um estudo em três capitais brasileiras. (Tese de Doutorado). Universidade Federal da Bahia, Salvador.

Arpini, D. M. (2003). Violência e exclusão: adolescência em grupos populares. Bauru: Edusc.

Broide, J. (2008). Psicanálise nas situaçôes sociais criticas: violência, juventude e periferia em uma abordagem grupal. Curitiba: Juruá.

Broide, J. (2010). Adolescência e violência: criação de dispositivos clínicos no território conflagrado das periferias. Revista Psicologia Politica, 10(19), 95106. Recuperado a partir de http://pepsic.bvsalud.org/scielo.php?script=sci_ arttext\&pid=S1519-549X2010000100009.

Brondani, R. P., \& Arpini, D. M. (2019). Experiências escolares de adolescentes em cumprimento de medida socioeducativa. Revista de Educação PUCCampinas, 24(1), 73-88. Recuperado a partir de http://periodicos.puccampinas.edu.br/seer/index.php/reveducacao/article/view/4228

Castel, R. (1997). As armadilhas da exclusão. In R. Castel, L. E. W. Wanderley, \& M. Belfiore-Wanderley (Org.). Desigualdade e a questão social. (pp. 17-50). São Paulo: Educ.

Cerqueira-Santos, E., Paludo, S. S., Schirò, E. D. B., \& Koller, S. H. (2010). Gravidez na adolescência: análise contextual de risco e proteção. Psicologia em Estudo, 15(1), 73-85. Recuperado a partir de http://www.scielo.br/scielo. php?script=sci_abstract\&pid=S1413-73722010000100009\&lng=en\&nrm =is o\&tlng=pt

Feijó, M. C., \& Assis, S. G. (2004). O contexto de exclusão social e de vulnerabilidades de jovens infratores e de suas famílias. Estudos de Psicologia, 9(1), 157-166. Recuperado a partir de http://www.scielo.br/scielo.php?script=sci_ arttext\&pid=S1413-294X2004000100017\&lng=en\&nrm=iso\&tlng=pt

Feltran, G. S. (2008). O legítimo em disputa: as fronteiras do "mundo do crime" nas periferias de São Paulo. Dilemas - Revista de Estudos de Conflito e Controle Social, 1(1), 93-126. Recuperado a partir de https://revistas.ufrj.br/index.php/ dilemas/article/view/7136 
Gomes, M. A., \& Pereira, M. L. D. (2005). Família em situação de vulnerabilidade social: uma questão de políticas públicas. Ciência \& Saúde Coletiva, 10(2), 357-363. Recuperado a partir de http://www.scielo.br/scielo.php?script=sci_ arttext\&pid=S1413-81232005000200013\&lng=en\&nrm=iso\&tlng=pt

Guimarães, I. B. (2011). Periferias e territórios sob efeitos conjugados da precarização: algumas tendências. Caderno CRH, 24(1), 89-104. Recuperado a partir de http://www.scielo.br/scielo.php?script=sci_arttext\&pid=S010349792011000400007\&lng=en\&nrm=iso\&tlng=pt

Instituto Brasileiro de Geografia e Estatística. (2015). Projeção da população do Brasil. Rio de Janeiro: IBGE. Recuperado a partir de https://brasilemsintese. ibge.gov.br/populacao/taxas-de-fecundidade-total.html

Kehl, M. R. (2008). A frátria órfã: conversas sobre a juventude. São Paulo: Olho d'Água.

Medeiros, F. C., \& Paiva, I. L. (2015). A convivência familiar no processo socioeducativo de adolescentes em privação de liberdade. Estudos e Pesquisas em Psicologia, 15(2), 568-586. Recuperado a partir de http://pepsic.bvsalud. org/scielo.php?script=sci_arttext\&pid=S1808-42812015000200008.

Minayo, M. C. S. (2014). O desafio do conhecimento: pesquisa qualitativa em saúde. (13a ed.). São Paulo: Hucitec.

Monteiro, L. P., \& Rocha, T. T. (2013). Experiências socioeducativas das famílias de adolescentes em conflito com a lei. In S. M. G. Sousa (Org.), Adolescentes autores de atos infracionais: estudos psicossociais. (pp. 59-84). Goiânia: Editora PUC Goiás.

Moreira, M. I. C., Passos, A. P. C. P., \& Pereira, C. C. (2012). A posição da família nas políticas públicas de proteção: oscilações entre o centro e a margem. In M. I. C. Moreira, \& S. D. M. S. Carellos. Famílias em vulnerabilidade social: épossivel auxiliar sem invadir? (pp. 29-48). Curitiba: CRV.

Oliveira, C. S. (2001). Sobrevivendo no inferno: a violência juvenil na Contemporaneidade. Porto Alegre. Sulina.

Oliveira, N. H. D. (2009). Recomeçar: famillia, filhos e desafios. São Paulo: Editora Unesp, Cultura Acadêmica.

Patto, M. H. S. (2010). A cidadania negada: politicas públicas e formas de viver. São Paulo: Casa do Psicólogo. 
Rocha, T. T. (2010). Os olhares maternos diante da medida socioeducativa de privação de liberdade em Goiás. (Dissertação de Mestrado), Pontifícia Universidade Católica de Goiás, Goiânia.

Rodrigues, D. J. S., \& Sousa, S. M. G. (2017). Sentidos de sociedade e violência para jovens pobres para periferia de Goiânia. In A. A. S. Oliveira (Org.). Psicologia Sócio-histórica e o contexto de desigualdade psicossocial: teoria, método e pesquisas. (pp. 193-210). Maceió: Edufal.

Rolim, M. (2016). A formação de jovens violentos: estudo sobre a etiologia da violência extrema. Curitiba: Appris.

Sales, M. A. (2007). Invisibilidade perversa: adolescentes infratores como metáfora da violência. São Paulo: Cortez.

Salles, L. M. F., Silva, J. M. A. P., \& Fonseca, D. C. (2014). Violência e inserção social do jovem de periferia urbana. Psicologia: Teoria e Prática, 16(3), 5868. Recuperado a partir de http://pepsic.bvsalud.org/scielo.php?script=sci_ arttext\&pid=S1516-36872014000300005\&lng=pt\&nrm=iso.

Santos, L. N., Mota, A. M. A., \& Silva, M. V. O. (2013). A dimensão subjetiva da subcidadania: considerações sobre a desigualdade social Brasileira. Psicologia: Ciência e Profissão, 33(3), 700-715. Recuperado a partir de http://www.scielo. br/scielo.php?script=sci_arttext\&pid=S1414-98932013000300014\&lng=pt \&nrm=iso

Sawaia, B. (1999). Introdução: exclusão ou inclusão perversa? In B. Sawaia (Org.). As artimanhas da exclusão: análise psicossocial e ética da desigualdade social. (pp. 7-16). (14a ed.). Petrópolis: Vozes.

Silvestre, L. P. F. (2013). Privação de liberdade e a criminalização da adolescência: um estudo sobre centro de socioeducação de Ponta Grossa. (Dissertação de Mestrado). Universidade Estadual de Ponta Grossa, Ponta Grossa.

Soares, L. E. (2004). Juventude e violência no Brasil contemporâneo. In R. Novaes, \& P. Vannucchi (Org.), Juventude e sociedade: trabalho, educação, cultura e participação. (pp. 130-159). São Paulo: Fundação Perseu Abramo.

Sousa, S. M. G., \& Peres, V. L. A. (2002). Famílias de camadas populares: um lugar legítimo para a educação/formação dos filhos. O Social em Questão: Revista do Departamento de Serviço Social da PUC-Rio, 7(1), 63-74. 
Souza, L. A., \& Costa, L. F. (2013). A significação das medidas socioeducativas para as famílias de adolescentes privados de liberdade. Psico-USF, 18(2), 277-287. Recuperado a partir de http://www.scielo.br/scielo.php?script=sci_ arttext\&pid=S1413-82712013000200011\&lng=pt\&tlng=pt

Tejadas. S. S. (2007). Juventude e ato infracional: as múltiplas determinaçôes da reincidência. Porto Alegre: Edipucrs.

Yin, R. (2005). Estudo de caso: planejamento e métodos. (3a ed.). Porto Alegre: Bookman.

Wanderley, M. B. (1999). Refletindo sobre a noção de exclusão. In B. Sawaia (Org.). As artimanhas da exclusão: análise psicossocial e ética da desigualdade social. (pp. 17-28). (14a ed.). Petrópolis: Vozes. 